\title{
2011 TOHOKU TSUNAMI RUNUP AND DEVASTATING DAMAGES AROUND YAMADA BAY, IWATE: SURVEYS AND NUMERICAL SIMULATION
}

\author{
$\underline{\text { Akio Okayasu }^{1} \text {, Takenori Shimozono }}{ }^{1}$, Shinji Sato ${ }^{2}$, Yoshimitsu Tajima ${ }^{2}$, Haijiang Liu ${ }^{3}$, \\ Tomohiro Takagawa ${ }^{4}$ and Hermann M. Fritz ${ }^{5}$
}

\begin{abstract}
Distributions of inundation and runup height for the 2011 off the Pacific coast of Tohoku Earthquake Tsunami were measured in and outside Yamada Bay located at the center of Iwate Prefecture, Japan. Numerical simulations were conducted to reproduce flow, inundation and runup height distributions. Surface elevation profiles recorded by the GPS wave gauges were used as the offshore boundary condition. In order to investigate characteristics of tsunami response to different geomorphological features, frequency separation was tried for the tsunami incident wave. It was found that the high frequency component was responsible for large tsunami height at narrow inlets and open bays, whereas the low frequency component had significant influence for inundation in closed bays.
\end{abstract}

Keywords: 2011 Tohoku Tsunami, Yamada Town, tsunami survey, tsunami simulation, GPS wave gauge

\section{INTRODUCTION}

On 11 March 2011, a magnitude $\mathrm{Mw}=9.0$ earthquake, the 2011 off the Pacific coast of Tohoku Earthquake, occurred off the coast of Japan's Tohoku region causing catastrophic damage and loss of life primarily by its tsunami (Japan Meteorological Agency, 2012). After The Southern Hyogo prefecture earthquake in $1995(\mathrm{M}=7.3)$, Japan had considerably improved its strength against earthquakes and appears to have succeeded given the relatively small damages, both in terms of properties and fatalities, by the 2011 off the Pacific coast of Tohoku Earthquake despite its large magnitude.

Regarding tsunamis, it was believed that the Japanese society had prepared well for them, especially in the Sanriku area (the northern Tohoku coastal area). Along the Sanriku coast, in the past 120 year they witnessed three major tsunamis: Meiji Sanriku Tsunami (1896), Showa Sanriku Tsunami (1933) and Chilean Tsunami (1960). Following investigations of Chilean Tsunami (Geographical Survey Institute, 1961), the Japanese government and local governments built protective structures, such as tsunami seawalls and breakwaters, along the northern Tohoku coast. In the meantime the plans for tsunami protection had been revised and the construction of tsunami protection structures completed at most cities and towns in the area. Soft measures such as tsunami evacuation plans were also provided for each of the local communities. This time, however, the tsunami brought massive destructions and loss of human lives. The primary reason was the large tsunami magnitude with water surface elevations significantly exceeding expected and design tsunami heights. According to the field surveys, the tsunami heights of the 2011 off the Pacific coast of Tohoku Earthquake Tsunami exceeded those of the past three major tsunamis in the region (Mori et al., 2012).

In order to provide efficient tsunami mitigation measures for potential future tsunamis, it is important to analyze the characteristics of the 2011 tsunami and the resulting damages. In the present study, distributions of inundation and runup heights for the tsunami were measured in and outside Yamada Bay located at the center of Iwate Prefecture, Japan. The survey was conducted during the period of April 10 to 13, 2011, essentially a month after the event. To investigate the relationship between the property of tsunami waveforms and the degree of destruction, numerical simulations were conducted to reproduce tsunami flow, inundation and runup heights. In the simulation, surface elevation profiles recorded by the GPS wave gauges installed about $20 \mathrm{~km}$ offshore were used as the offshore boundary condition. Frequency separation was considered in the simulations for the incident tsunami waves to investigate characteristics of tsunami response to different geomorphological features.

\section{OBSERVATION OF DAMAGES AND SURVEY OF TSUNAMI TRACES}

\section{Overview of tsunami height distribution in the survey areas}

Figure 1 shows the distribution of tsunami heights (inundation and runup heights) for the 2011 off the Pacific coast of Tohoku Earthquake Tsunami collected by the 2011 Tohoku Earthquake Tsunami Joint Survey Group (TTJST, 2012). The red band in the figure indicates the target area of this study. The general envelop of tsunami heights shows that very high traces close to $40 \mathrm{~m}$ were found between 39 to

\footnotetext{
${ }^{1}$ Dept. of Ocean Sciences, Tokyo University of Marine Science and Technology, Minato-ku, Tokyo 108-8477, Japan

${ }^{2}$ Dept. of Civil Engineering, University of Tokyo, Bunkyo-ku, Tokyo 113-8656, Japan

${ }^{3}$ Dept. of Ocean Science and Engineering, Zhejiang University, Hangzhou, Zhejiang 310058, China

${ }^{4}$ APaC-CDR, Port and Airport Research Institute, Nagase, Yokosuka City, Kanagawa 239-0826, Japan

${ }^{5}$ School of Civil and Environmental Engineering, Georgia Institute of Technology, Savannah, GA 31407, USA
} 
40 degree in latitude and the height decreased both to north and south. However a localized reduction is noted at approximately 39.4 ${ }^{\circ} \mathrm{N}$ around Yamada Bay. As described below, Yamada Bay has a narrow bay mouth which reduced the tsunami height.

Table 1 provides statistics on fatality rates for cities and towns in Iwate Prefecture locating between $39^{\circ}$ and $40^{\circ} \mathrm{N}$ in latitude. Although the areas inside Yamada Bay were partially protected by peninsulas and the narrow bay opening, the fatality rate of $4 \%$ for Yamada Town appears relatively high. The exposed regions further south experienced characteristic tsunami heights of $15 \mathrm{~m}$ resulting in larger fatality rates at Otsuchi Town and Rikuzen-Takata City (Liu et al., 2012). To consider the factors which affected the damages in Yamada Town, a tsunami trace survey was carried out in and around Yamada Bay areas.

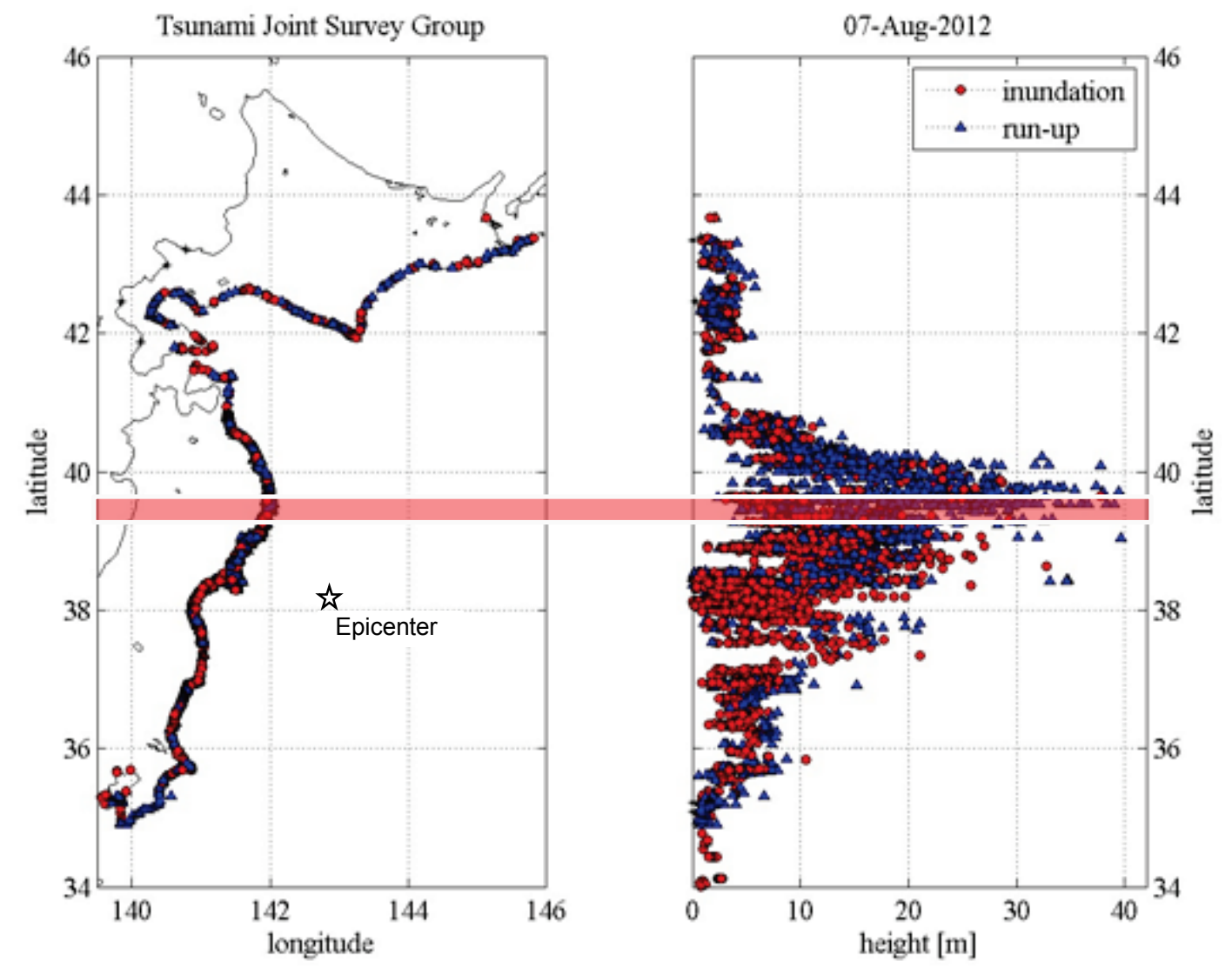

Figure 1. Tsunami survey results collected by the 2011 Tohoku Earthquake Tsunami Joint Survey Group (TTJSG) along the coastline of north-eastern Japan (The original figure was provided by TTJSG). The red band shows the area covered by the present study.

\begin{tabular}{|c|c|c|c|}
\hline \multicolumn{3}{|c|}{$\begin{array}{c}\text { Table 1. Ratios of Dead and Missing to Population in Iwate Pref. (as of September 12, 2012) } \\
\text { (The data were provided by Iwate Prefecture) }\end{array}$} \\
\hline $\begin{array}{c}\text { Name of city, town or } \\
\text { village (from North) }\end{array}$ & $\begin{array}{c}\text { Number of } \\
\text { dead and missing }\end{array}$ & Population in 2010 & $\begin{array}{c}\text { Ratio of dead and missing } \\
\text { to population }\end{array}$ \\
\hline Noda Village & 38 & 4,632 & $0.82 \%$ \\
Tanohata Village & 29 & 3,843 & $0.75 \%$ \\
Miyako City & 516 & 59,442 & $0.87 \%$ \\
Yamada Town & 755 & 18,625 & $4.05 \%$ \\
Otsuchi Town & 1,276 & 15,277 & $8.35 \%$ \\
Kamaishi City & 1,041 & 39,578 & $2.63 \%$ \\
Ofunato City & 421 & 40,738 & $1.03 \%$ \\
Rikuzen-Takata City & 1,778 & 23,302 & $7.63 \%$ \\
\hline
\end{tabular}


Figure 2 shows a satellite image around Yamada Bay together with measured runup and inundation heights of the tsunami. The survey areas are characterized by three different geomorphologic features: Omoe Peninsula represented by an inlet at Aneyoshi to the north, Yamada Bay at the center and wide Funakoshi Bay facing to the epicenter to the south.

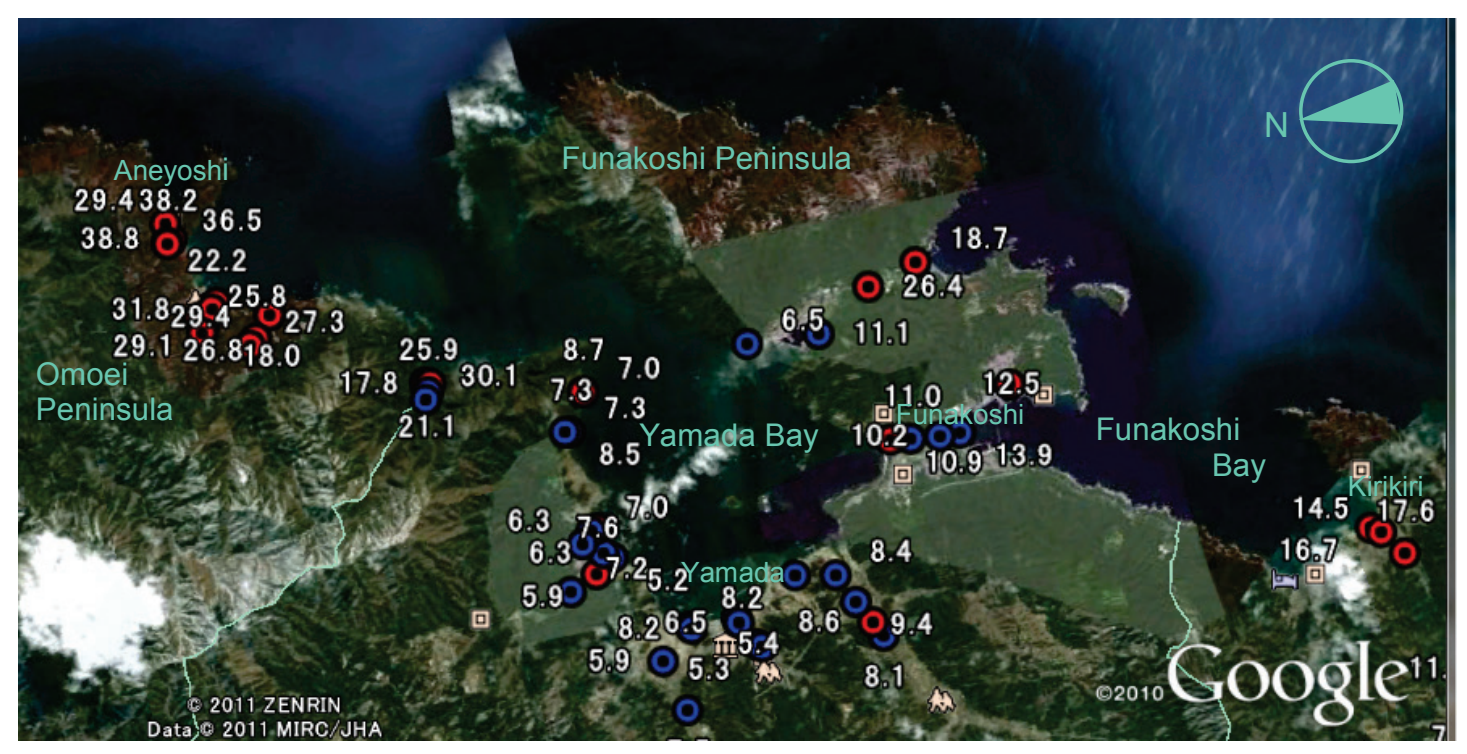

Figure 2. Tsunami survey results around Yamada Bay (Image processed by Google Earth). Some extreme tsunami runup heights were observed outside Yamada Bay. The largest runup was measured at the end of a small funnel-shape inlet at Aneyoshi.

\section{Aneyoshi at Omoe Peninsula}

On the exposed east coast of the Omoe Peninsula the average tsunami height was 15 to $20 \mathrm{~m}$ at the shoreline as shown in Figure 2. All villages there were impacted by extreme runup heights of more than $25 \mathrm{~m}$ and residential houses at lower elevation were completely washed away. The highest runup, approaching $40 \mathrm{~m}$ with an inundation distance of $500 \mathrm{~m}$, was measured at the inlet of Aneyoshi. It locates at the bottom of a small funnel-shape inlet which concentrates the energy of tsunami and amplifies its height (Photograph 1).

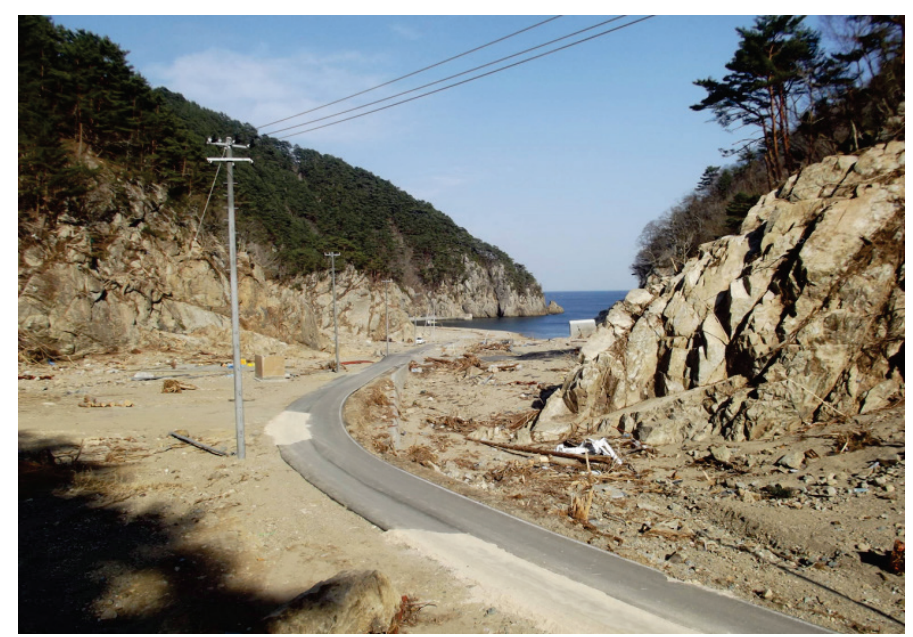

Photograph 1. Small valley at the end of a funnel-shape inlet of Aneyoshi. The electric posts seen in the photograph were built after the tsunami. Note the erosion down to bedrock. (Photograph taken on April 13, 2011) 
Figure 3 shows an overview of the Aneyoshi valley with the tsunami height exceeding $20 \mathrm{~m}$ at the mouth of the gulch along the coastline of Aneyoshi Inlet. The small white rectangles in the satellite image are concrete caissons that formed the inlet breakwaters of Aneyoshi Fishery Port. The tsunami penetrated upstream along the winding gulch of Aneyoshi reaching up to runup heights of $38 \mathrm{~m}$ at an inundation limit located about $200 \mathrm{~m}$ downstream of the Aneyoshi village visible at the upper-left corner of the satellite image.

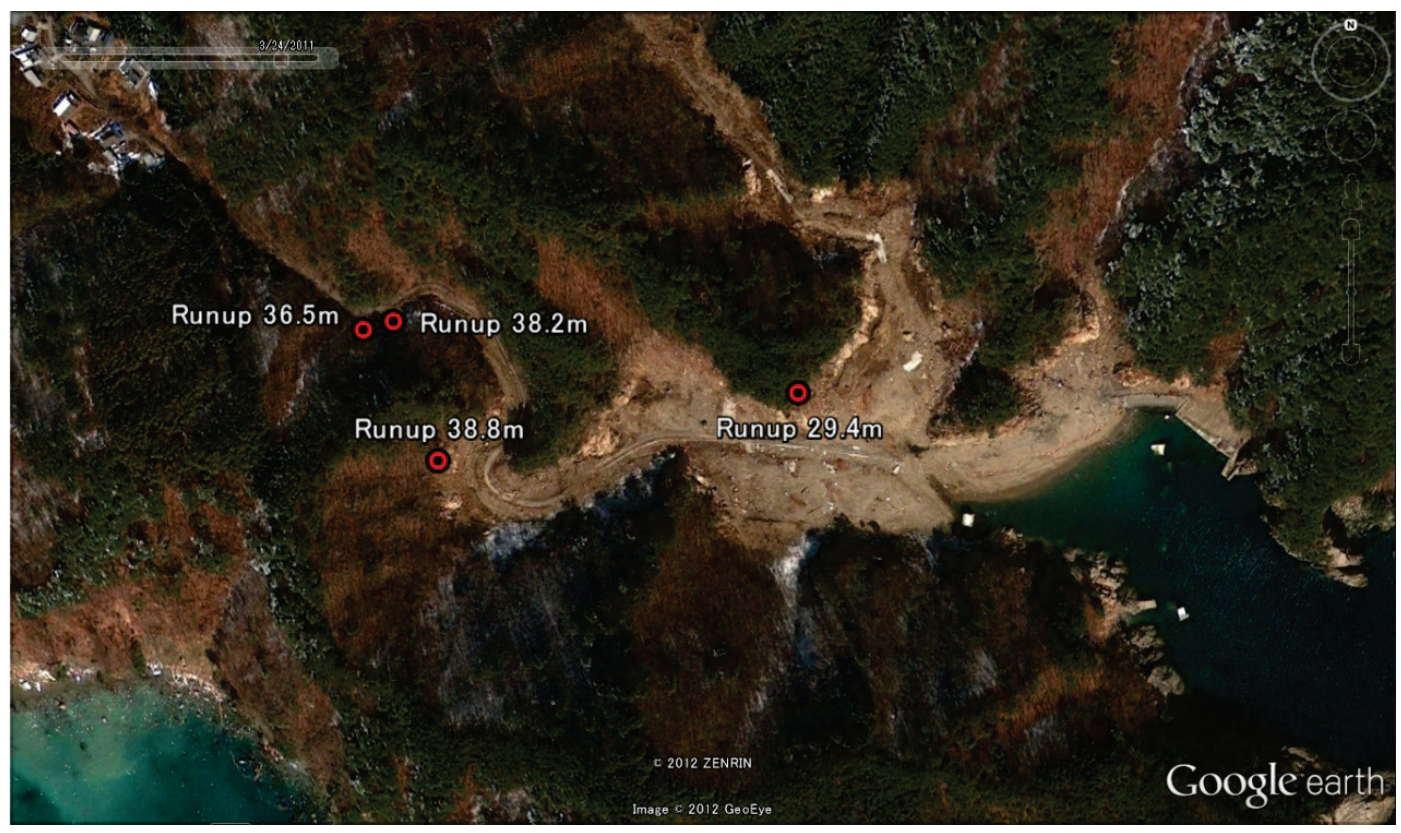

Figure 3. Satellite image of Aneyoshi Valley (Image processed by Google Earth). The markers show measured tsunami heights. The houses at the upper-left corner form Aneyoshi Village which had been relocated to the present location after Showa Sanriku Tsunami in 1933.

The village of Aneyoshi is famous for its stone monument located downstream of the village but $50 \mathrm{~m}$ upstream from the runup point of the 2011 tsunami. It tells that no house should be built below the monument. The village of Aneyoshi has a history that it was completely washed away by two major historic tsunamis in 1896 and 1933. After the Showa Sanriku tsunami in 1933, the village decided to relocate upstream to the current location which resulted in zero fatality during the 2011 event despite the extraordinary tsunami runup.

\section{Yamada Town at the head of Yamada Bay}

Yamada Bay is characterized by a narrow, only $940 \mathrm{~m}$ wide bay-mouth whereas the approximate width of the bay is $4 \mathrm{~km}$. The bay is surrounded by two peninsulas: Omoe Peninsula to the north and Funakoshi Peninsula to the south. In terms of orientation towards the epicenter Yamada Bay locates behind Funakoshi Peninsula.

In contrast to the large tsunami heights on Omoe Peninsula, the tsunami height inside Yamada Bay was relatively small, generally around 6 to $9 \mathrm{~m}$. It is considered that the narrow bay-mouth reduced the tsunami height and Funakoshi Peninsula worked as a natural barrier sheltering Yamada Bay.

Yamada Town located at the head of Yamada Bay however suffered significant loss of life. Photograph 2 shows the devastating damage in the Osawa Area of Yamada Town at the north side of the Yamada Bay. The ratio of dead or missing to its population is around $4 \%$, which is high among the cities and towns along the Sanriku Coast. Yamada Town had moderately large lowland areas along the bay and was protected by a non-uniform combination of old and new tsunami seawalls. The height of the old seawall was $4.0 \mathrm{~m}$, whereas the design height of the new one was $6.6 \mathrm{~m}$ above the local mean sea level. It should be noticed that the effective heights of the seawalls may be tens of centimeters lower than their design heights because of the coseismic landlevel subsidence. The tsunami height marginally overflowed the new seawall sections. Unfortunately the lateral old seawall segments allowed massive overtopping and flooding into the town resulting in property damages and loss of life (Photographs 3 and 4). 


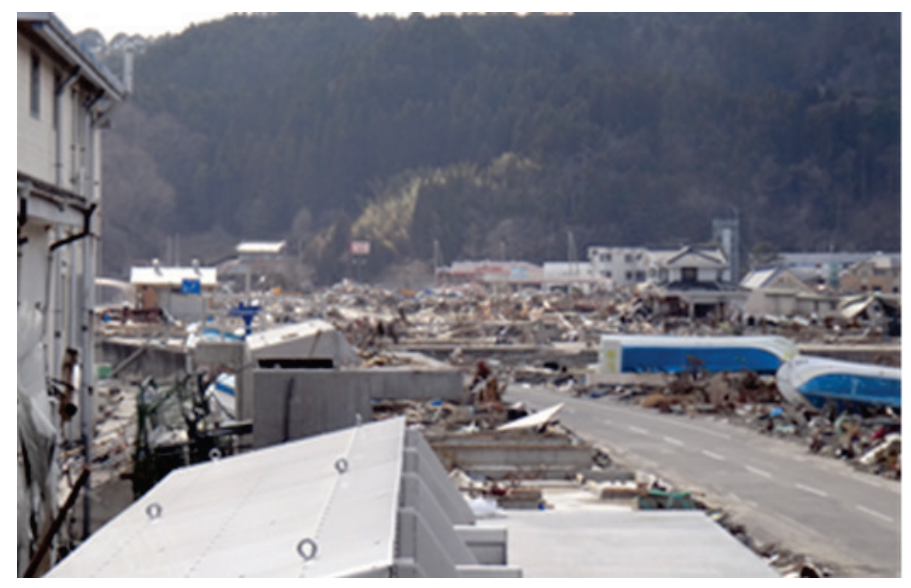

Photograph 2. View from top of the new seawall overlooking the Osawa Area of Yamada Town toward the old seawall section to the west. The old section was significantly lower with a height of $4.0 \mathrm{~m}$ above MSL compared to the new $6.6 \mathrm{~m}$ high section.

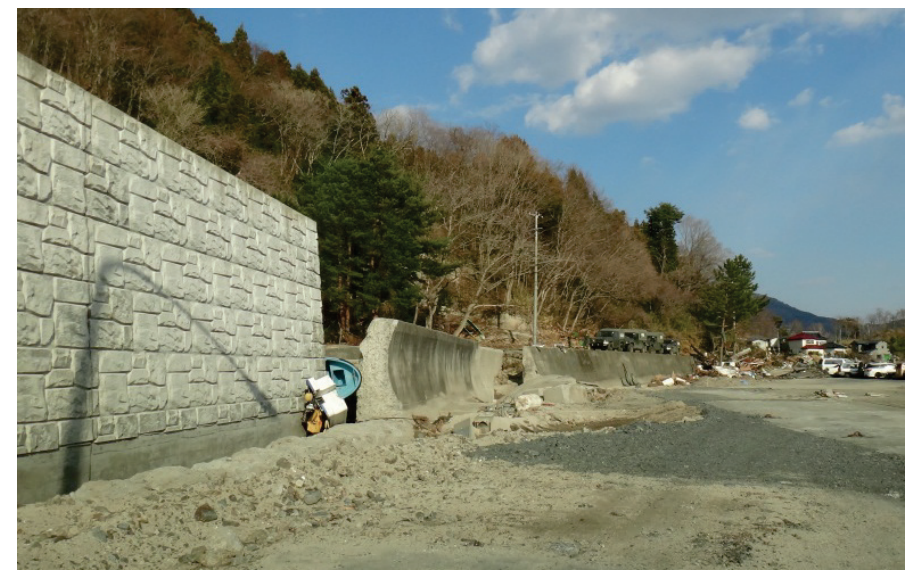

Photograph 4. Open end of the new seawall section at Osawa Area of Yamada Town. The old seawall at the transition was broken by the tsunami. The road passing though the opening leads to northern coastal villages on Omoe Peninsula.

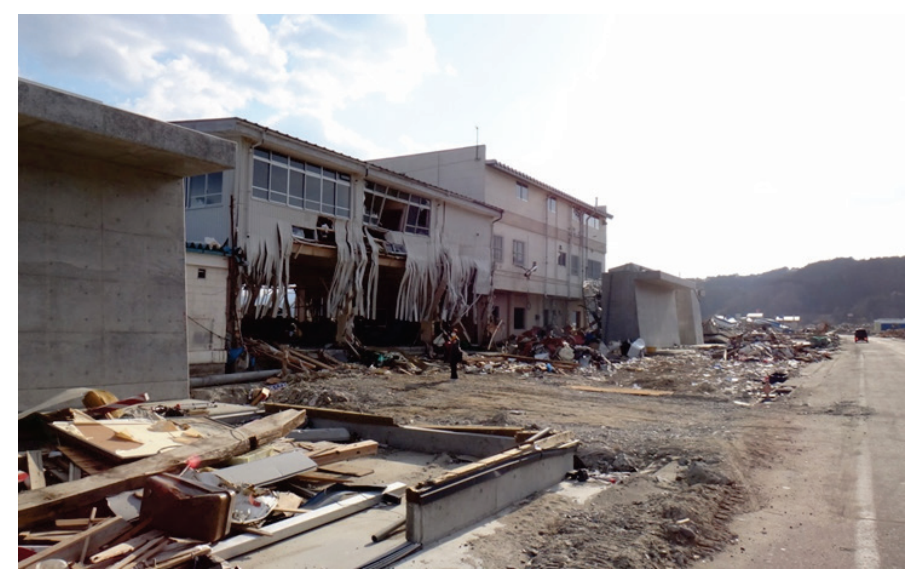

Photograph 3. Gap between new seawall segments at Osawa Fishery Port of Yamada Town. The tsunami flowed into the residential Osawa Area through the buildings of Osawa Fishery Port. 
In the Yamada Area of Yamada Town which is at west of the bay and facing to the bay entrance, the tsunami heights were slightly larger with typical values of 8 to $9 \mathrm{~m}$ with extremes approaching $10 \mathrm{~m}$ at some places (Photograph 5). The Yamada Area was mostly behind the new seawall, which the tsunami overtopped by 2 to $3 \mathrm{~m}$ resulting in sufficient flow rates over the seawall to flush wooden houses within a distance of $500 \mathrm{~m}$ from the coastline given the low elevation of the hinterland. Considering the height of the incoming tsunami, it can be concluded that the damage at Yamada Town was relatively large.

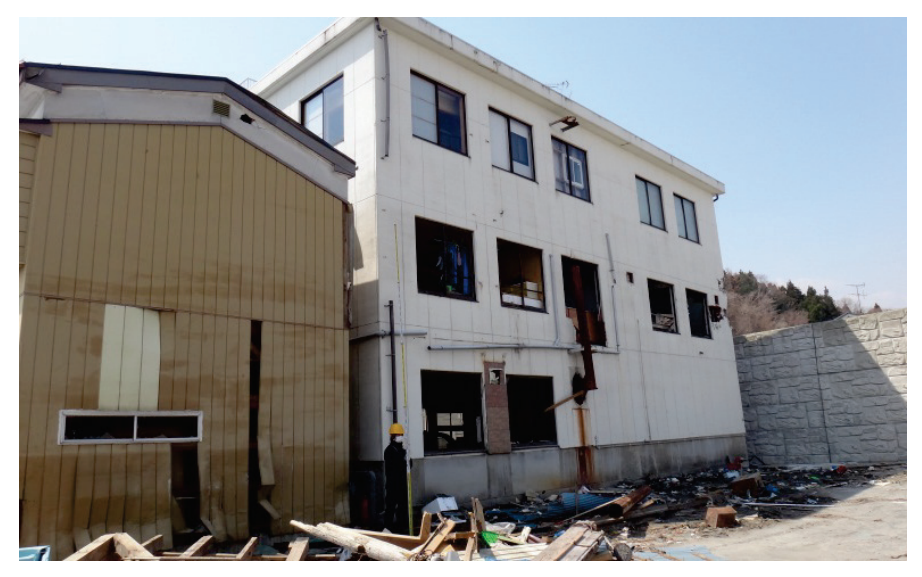

Photograph 5. An inundated building just outside the new seawall of Yamada Fishery Port of Yamada Town. A clear mudline watermark, slightly above the top of the second-floor window frames, indicated a tsunami height of $8.7 \mathrm{~m}$, more than $2 \mathrm{~m}$ higher than the seawall.

\section{Funakoshi and Kirikiri}

The tsunami height inside Yamada Bay was relatively small, generally around 6 to $9 \mathrm{~m}$, as described above. The only exception was the base of Funakoshi Peninsula where tsunami coming from the south overwashed the base of the Peninsula and caused massive destruction in the area. At Funakoshi Bay

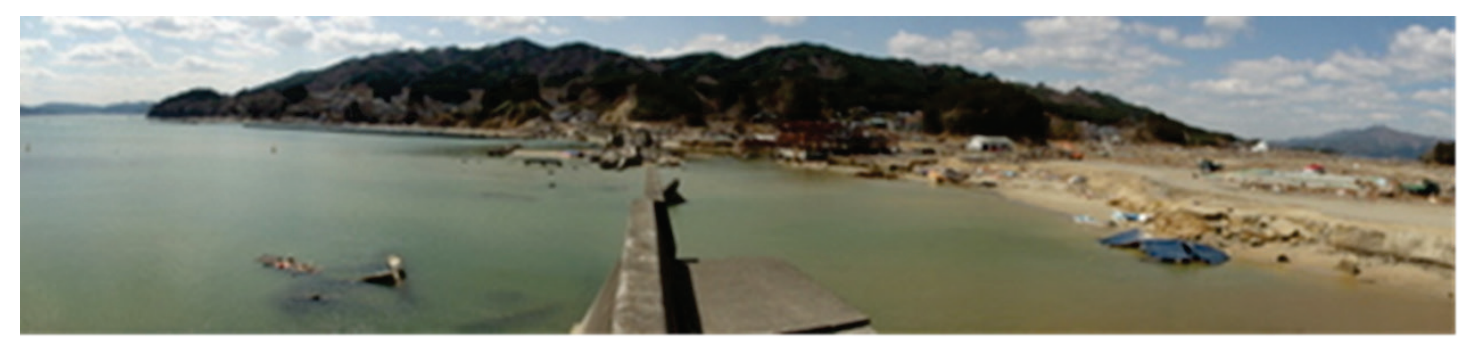

Photograph 6. Broken seawall facing to Funakoshi Bay at South of Funakoshi Area. The height of the seawall was $7.4 \mathrm{~m}$ above mean sea level.

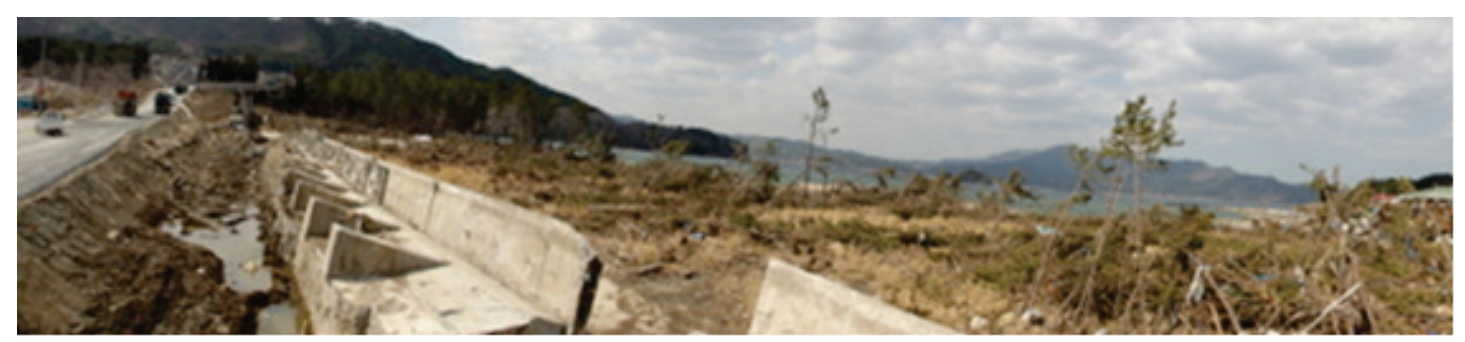

Photograph 7. Coastline facing to Yamada Bay at North of Funakoshi Area. The seawall and trees collapsed in northern direction (right in the photograph) indicating a northward directed main tsunami force. 
with a wide opening facing southeast to the epicenter, the average tsunami height at the shoreline was estimated to about $15 \mathrm{~m}$. Seawalls at the south side of Funakoshi Area facing to Funakoshi Bay fell either seaward (south) or landward (north) indicating strong flow velocities during runup and drawback phases (Photograph 6). On the contrary, as seen in Photograph 7, seawalls at the north side of Funakoshi Area which were facing to Yamada Bay all fell seaward (north). It can be concluded that the flow originating from Funakoshi Bay was dominant in Funakoshi Area.

The exposed areas south of Funakoshi Bay such as Kirikiri also experienced tsunami runup of more than $15 \mathrm{~m}$. Photograph 8 gives an idea how large and strong the tsunami was in Kirikiri Town. The measured elevation of the road surface of the overpass in the photograph and the base elevation of it were $8.8 \mathrm{~m}$ and $5.1 \mathrm{~m}$ from the mean sea level, respectively. A trace found on the roof of a four-story reinforced concrete building in the right of the photograph was $16.2 \mathrm{~m}$ above the sea level. At the top of the overpass, the parapets were bent toward the land side (Photograph 9), whereas they were bent toward the sea side at the lower part of the overpass (Photograph 8). These alternating bending directions suggest that the landward tsunami inflow during the runup phase was dominant at high locations, while the seaward outflow during the drawback phase was channelized in low lying areas. Extreme outflow current velocities have been reported at other locations such as Kesennuma (Fritz et al., 2012).

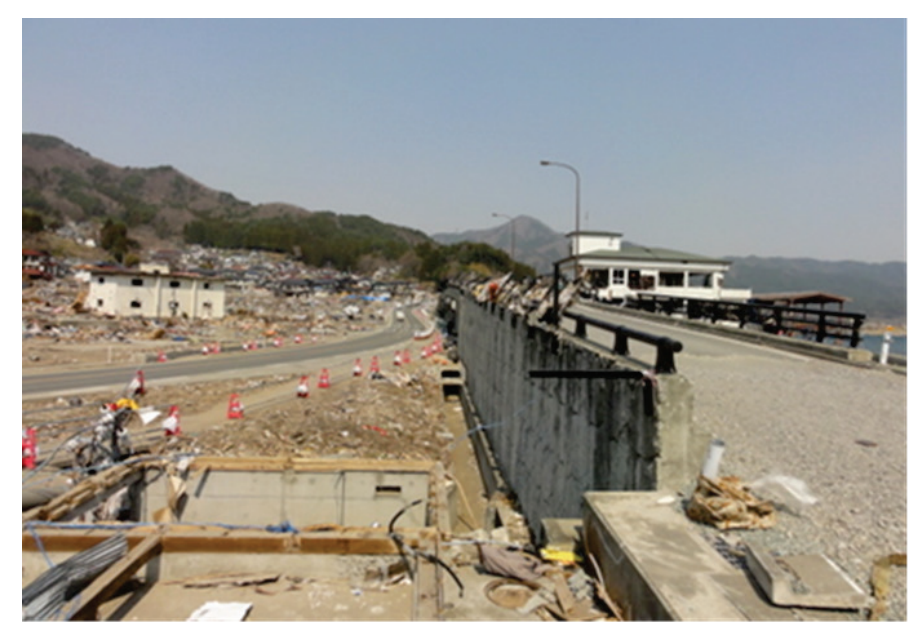

Photograph 8. Kirikiri Town flushed by the tsunami at the left. A tsunami trace at $16.2 \mathrm{~m}$ was found on the roof of the seaward RC 4-story building.

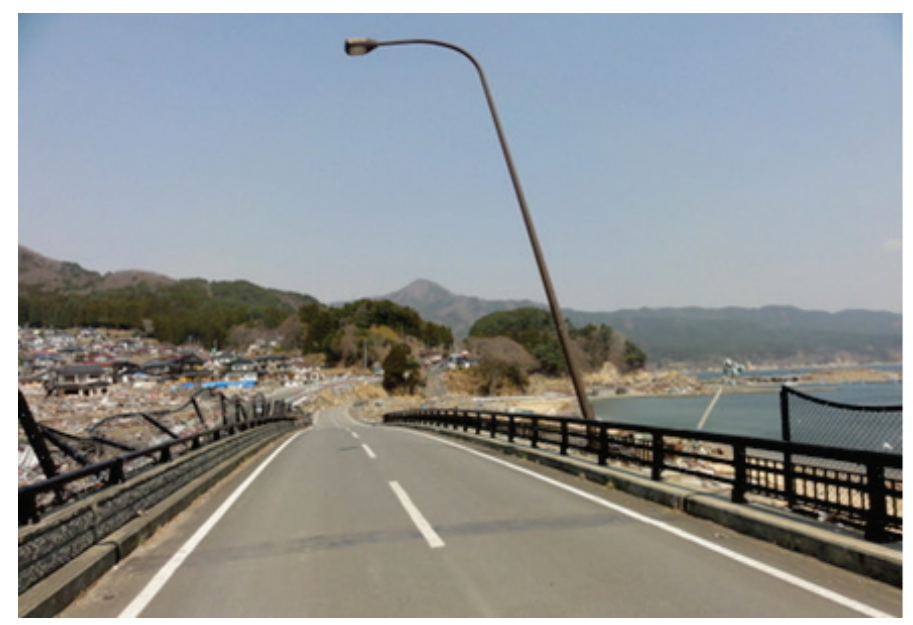

Photograph 9. At the top of the overpass, the lighting post and parapets were bent landwards, which is attributed to dominant inflow during the runup phase. 


\section{NUMERICAL SIMULATION WITH GPS WAVE GAUGE RECORDS}

\section{Method of simulation and incident wave condition}

As described in the previous section, the study area can be divided into three regions in terms of their geomorphological features. The first region is the eastern side of Omoe Peninsula, which has small inlets facing to the Pacific Ocean. In the region, the tsunami runup heights were more than $20 \mathrm{~m}$ at each of the inlets. The second region is formed by small flat plains of Yamada Town surrounding Yamada Bay which has a narrow bay mouth. The tsunami energy passing through the mouth was limited resulting in heights of 6 to $9 \mathrm{~m}$ at the shoreline. The third region is areas facing to Funakoshi Bay along which the tsunami heights were around $15 \mathrm{~m}$. The distribution of the tsunami heights is considered to be affected by the geomorphological features in the three regions.

A numerical simulation was carried out to see the characteristics of tsunami responses in the regions. The tsunami source generated by the 2011 off the Pacific coast of Tohoku Earthquake was very large and unique. It was estimated to be a combination of a large flat elevation of sea bottom and a relatively narrow and sharp peak generated along the Japan Trench (e.g. Fujii et al., 2011). This complex feature of the tsunami source caused rather complicated tsunami responses depending on location specific character in geomorphology.

The calculation was conducted by using a set of non-linear shallow water equations with bottom friction terms based on the Manning's formulation (Shimozono et al. 2012). Figure 4 shows the modeling domain and corresponding bathymetry, which was obtained from the electronic navigational chart issued by the Hydrographic and Oceanographic Department, Japan Coast Guard. The landward topography was given by the digital elevation map of $50 \mathrm{~m}$ grids provided by the Geospatial Information Authority of Japan. Since the calculation area was locally confined, a Cartesian coordinate with a grid size of $50 \mathrm{~m}$ was used for simulation. Accordingly, the bathymetry data were also converted into $50 \mathrm{~m}$ grid data. The seawalls along the shorelines were not considered unless they are reflected in the digital elevation map. The coastal subsidence by the earthquake was neglected.

The incident wave condition was estimated from water surface elevation data observed by GPS wave gauges located at around $20 \mathrm{~km}$ offshore. The detailed gauge positions are given in Figure 5 . In the present simulation, the water surface elevations observed by GPS 1 (Iwate North) and 2 (Iwate South) were used. The large, sharp peak of more than $6 \mathrm{~m}$ was clearly detected by the wave gauges at around 25 minutes after the earthquake. The offshore boundary of the calculation region was set at $y=0$ in Figure 4 and a wave form linearly interpolated in $x$-direction was introduced at the boundary.

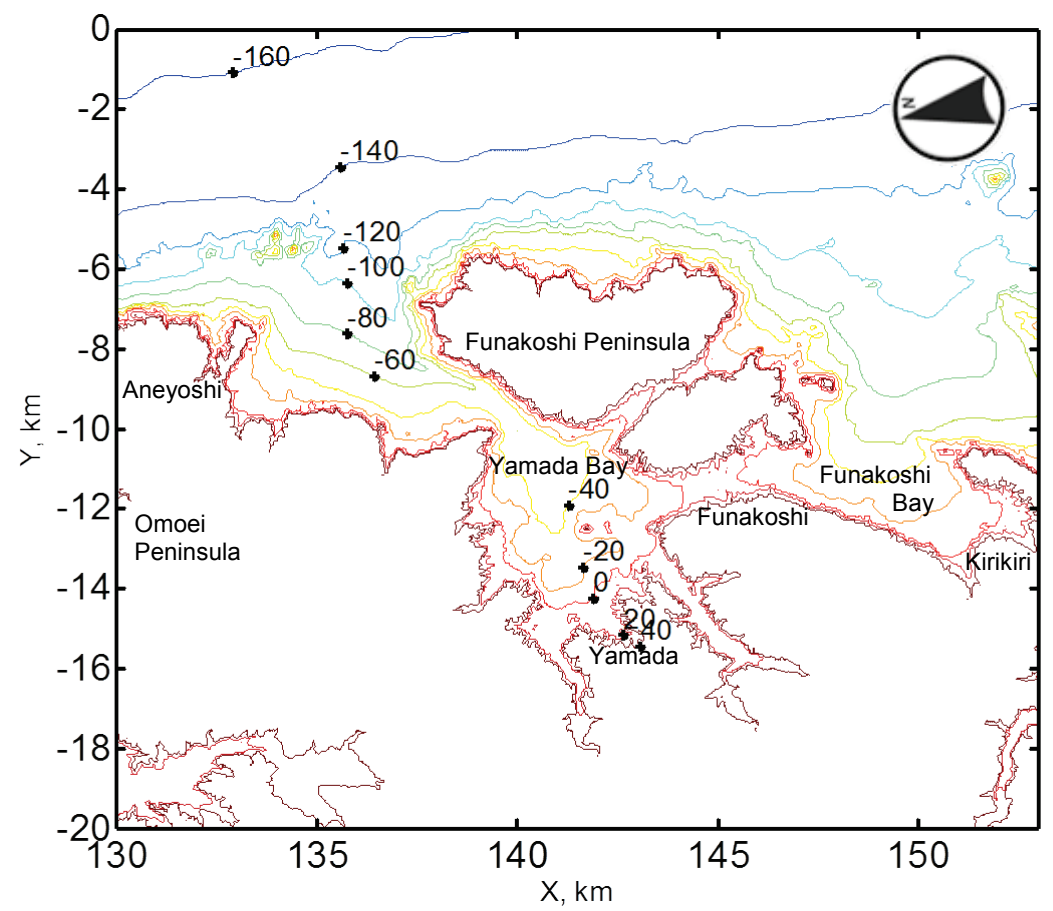

Figure 4. Bathymetry around Yamada Bay. The width of the bay mouth is $940 \mathrm{~m}$. The neck of Funakoshi Peninsula has a topographic elevation of less than $5 \mathrm{~m}$. 

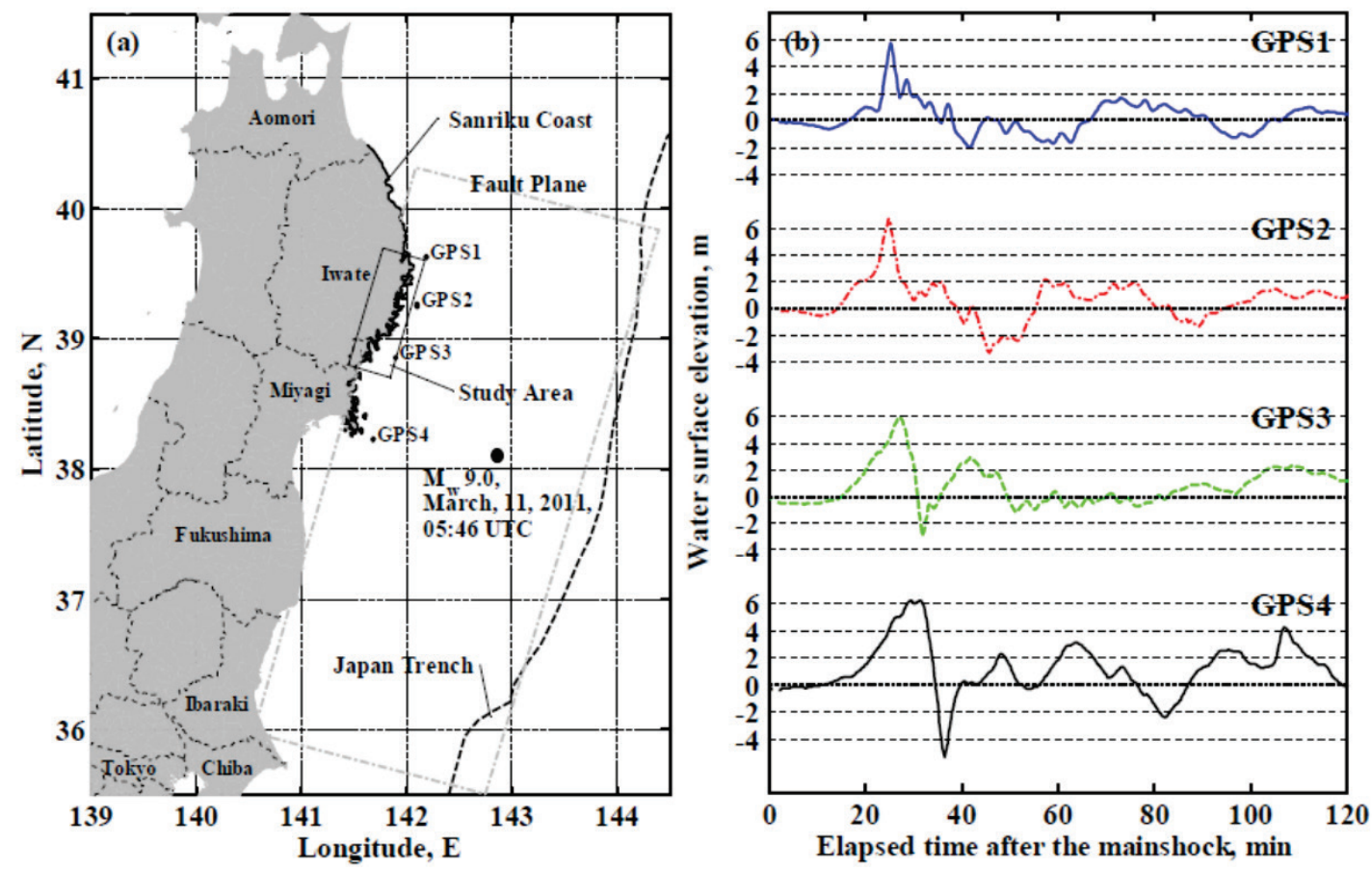

Figure 5. Left: Locations of GPS wave gauge recordings used for the numerical calculation. The target area of the present study locates at the coast between GPS1 and GPS2. Right: Measured water surface elevation used as incident waves at the seaward boundary in the simulation.

Calculated inundation, runup and drawdown

Figure 6 gives the maximum runup and drawdown of the tsunami calculated by the numerical model in comparison to the inundated areas evaluated from satellite imagery by Geospatial Information

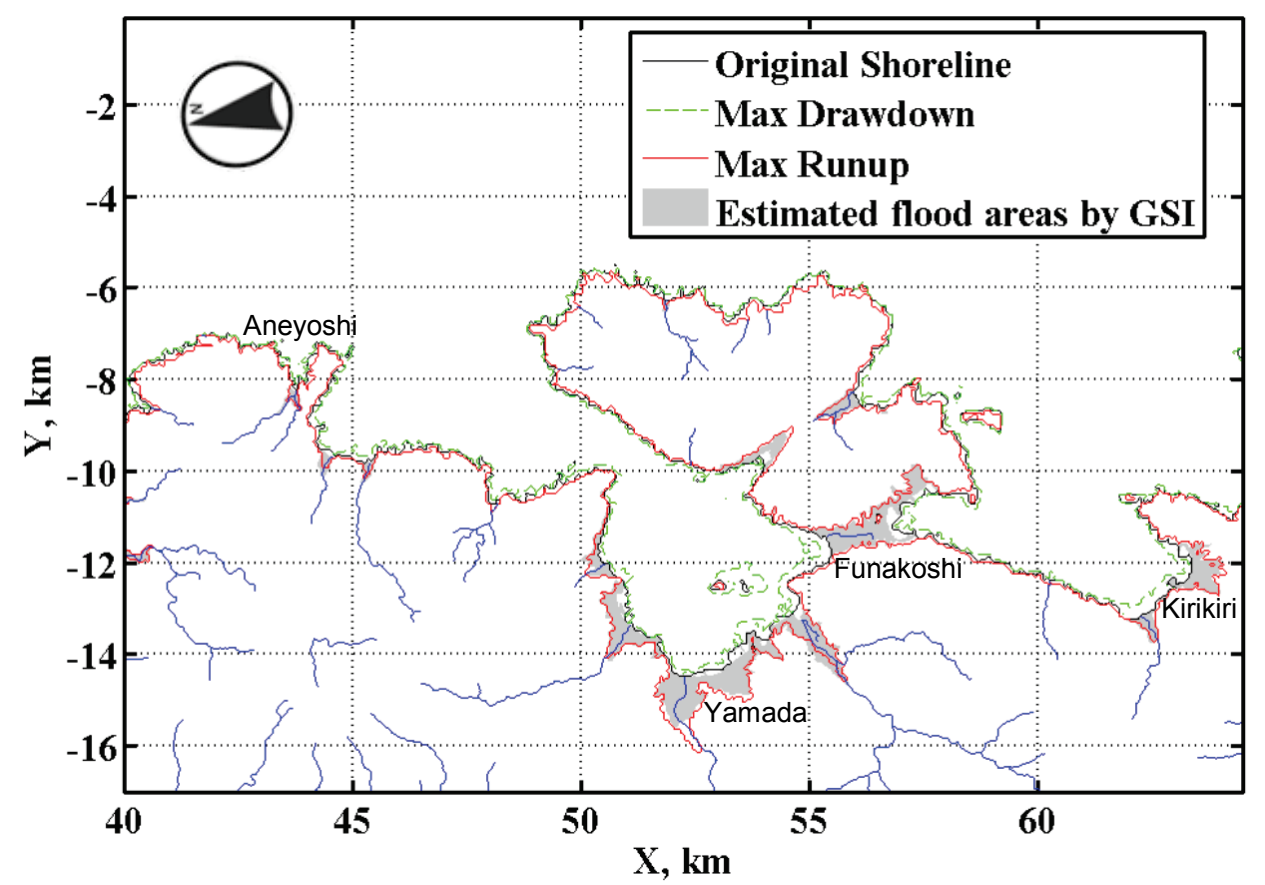

Figure 6. Simulated maximum runup and drawdown by in comparison with inundated areas evaluated from satellite images by GSI. 
Authority of Japan (GSI). In comparison the numerical model successfully reproduces the extent of flooded areas along the intricate coastline. As for the water surface elevation, Figure 7 shows an example of calculated water surface elevation in Yamada Bay. The calculated maximum elevation at the shoreline was around $10 \mathrm{~m}$, whereas the measured inundation heights at nearby locations at Yamada Port were within 8.7 to $9.5 \mathrm{~m}$ (TTJSG, 2012). The calculation tends to slightly overestimate the inundation heights on the flat plains (see also the top panel of Figure 10).

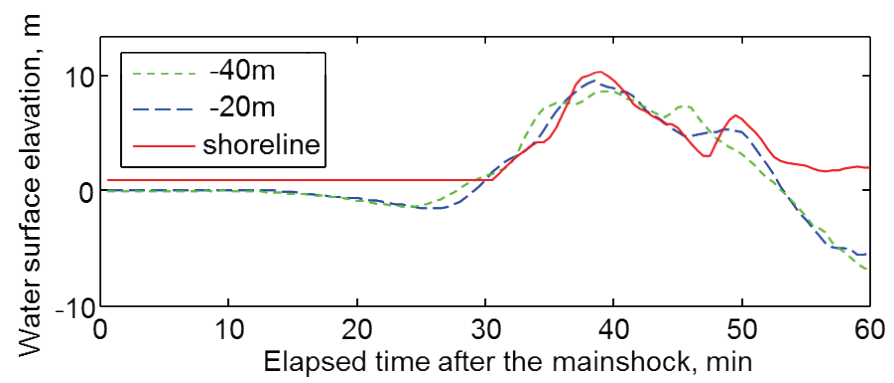

Figure 7. Calculated water surface elevation in Yamada Bay. The positions are shown in Figure 4. The largest elevation at the shoreline is about $10 \mathrm{~m}$ which is approximately $10 \%$ larger than the measured inundation depths at the nearbv locations.

\section{Separation of long and short wave components of incident wave}

Fujii et al. (2011) evaluated that the initial tsunami waveform for the 2011 off the Pacific coast of Tohoku Earthquake. The tsunami was produced by the combination of a very large displacement near the trench axis (1986 Meiji Sanriku type) and a deeper interplate slip along the southern Sanriku-oki, Miyagi-oki, and Fukushima-oki regions (869 Jogan type). It is considered that the former slip created
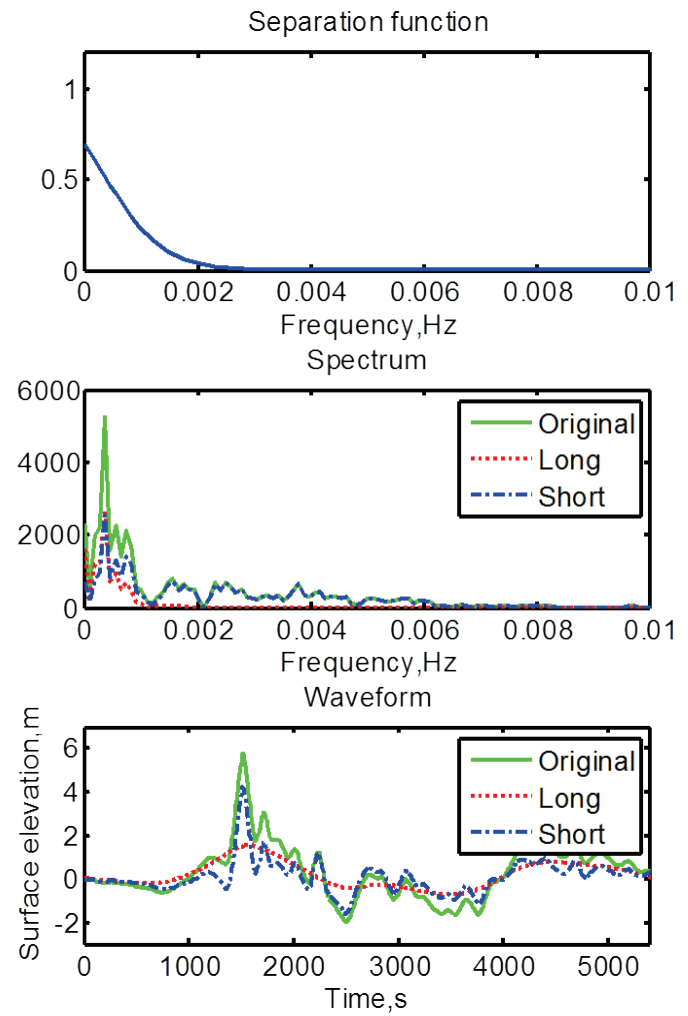

Figure 8. Separation of long and short wave components of the incident waveforms. Top: Frequency filter applied to the separation. Middle: Power spectra of each waveform in frequency domain. Bottom: Separated waveforms. 
the sharp and quite large peak of the incident tsunami wave measured by the GPS wave gauges shown in Figure 5, while the latter was primarily responsible for the long and relatively low, but still considerably large, surface elevation. In order to investigate the characteristics of resultant tsunami height distribution in the three geomorphologically different regions, tsunami responses for each of those two different tsunami sources should be examined. The analysis may be of guidance in taking appropriate measures for possible future tsunamis in the regions, and a reference for other potentially tsunami-hazardous areas.

To separate the long and short waves for the tsunami, the frequency separation was adopted. The top panel of Figure 8 gives the frequency filter used in the present study. The middle panel is the frequency spectra of the separated long and short waves for the waveform measured by GPS 1. Since the separation function doesn't take 1 at $0 \mathrm{~Hz}$, the short component still has a certain amount of energy for very low frequency. The bottom panel gives the original and separated waveforms for the incident wave at GPS 1. Since the tsunami generated by the large slip near Japan Trench axis took some time to reach the GPS wave gauges, the separated short-period wave was modified to exclude the initial change of surface elevation at the gauge. The waveforms actually applied to the calculation are shown in Figure 9 for both GPS 1 and 2. For these separated waveforms, the maximum elevations of short and long-period components were 4.1 to $4.3 \mathrm{~m}$ and 1.8 to $2.3 \mathrm{~m}$, respectively.
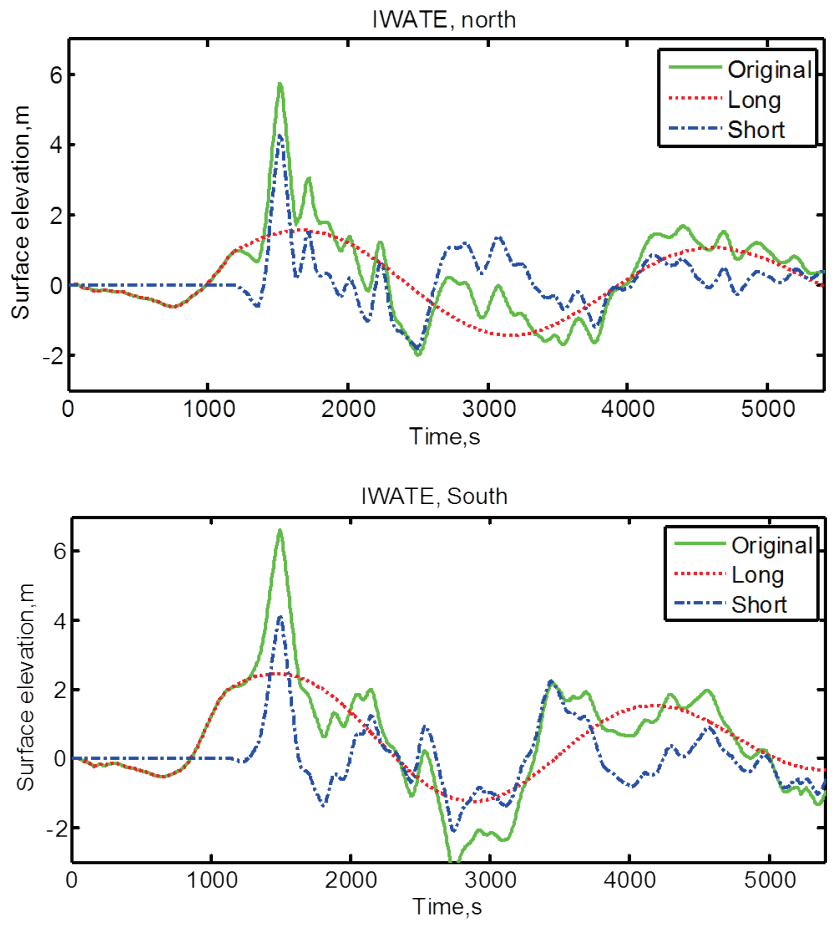

Figure 9. Wave forms given at the seaward boundary of the calculation domain. Long and short components were separated by the frequency filter shown in Figure 7 except at the beginning.

Tsunami responses and frequency dependencies in each region

The maximum water surface elevation calculated with the original incoming wave and the separated short and long wave components are shown in Figure 10. For the original waveform, the tendency of runup distribution is well reproduced, although very high runup at the bottom of funnel-shape inlets is considerably underestimated. It is considered that the simulation underestimates the runup of extreme heights over steep slopes, such as at Aneyoshi where the calculated runup height was less than $30 \mathrm{~m}$, presumably beyond the applicable range of the model equations.

By comparing the middle and bottom panels of Figure 10, it is found that the short wave component caused high inundation and runup at the small inlets and flat plains directly facing to the Pacific Ocean such as Aneyoshi and others in Omoe Peninsula, Funakoshi and Koyadori, which is north of Funakoshi and Kirikiri. On the contrary, the effect of the long wave component was dominant inside Yamada Bay. 

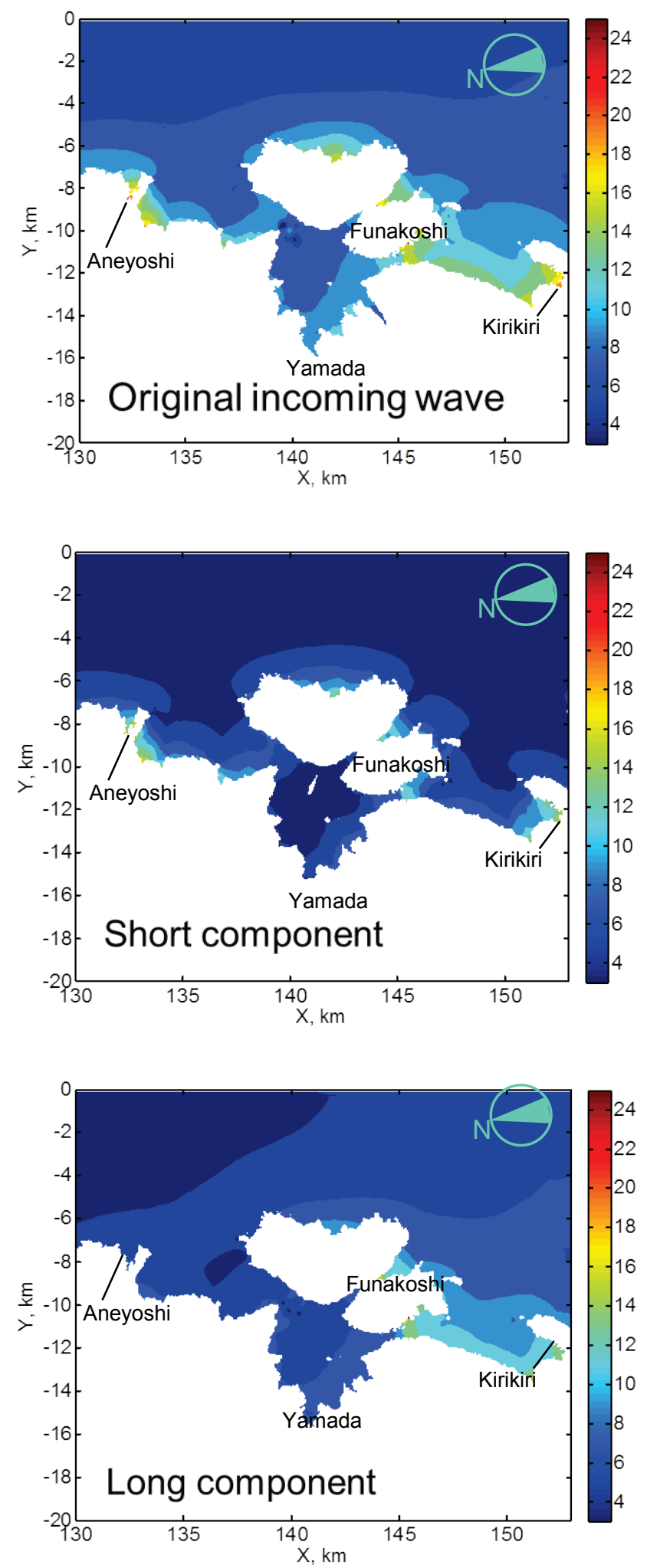

Figure 10. Result of numerical simulation. Top: Maximum water surface elevation calculated by the original wave. The very high runup height outside of the bay was underestimated, while the inundation height in Yamada Bay is reproduced. Middle: Calculation by the short period component only. Bottom: Calculation by the long period component only. 
The reduced amplitude for the short wave in Yamada Bay can be explained by the narrow bay entrance, which may act as a regulator for high frequency waves. The surface elevations calculated for the original, the long component and the short component at the depth of $40 \mathrm{~m}, 20 \mathrm{~m}$, and the shoreline of Yamada Bay (see Figure 4 for their locations) are shown in Figure 11. At the depth of $40 \mathrm{~m}$ which is almost at the center of the bay, the long component is fairly small (the bottom panel). It becomes however almost comparable to the long wave component at the shoreline probably due to the shallow water deformation (the top panel). It should be noted here that since the calculation is based on the nonlinear shallow water equations, the sum of the long and short wave elevation components is not the same as that by the original waveform. Although the maximum water elevations for long and short components are comparable, the duration of high water level for the short component is much shorter than that for the long component. It is therefore concluded that most of the water overflowing into the town was brought by the long wave component.

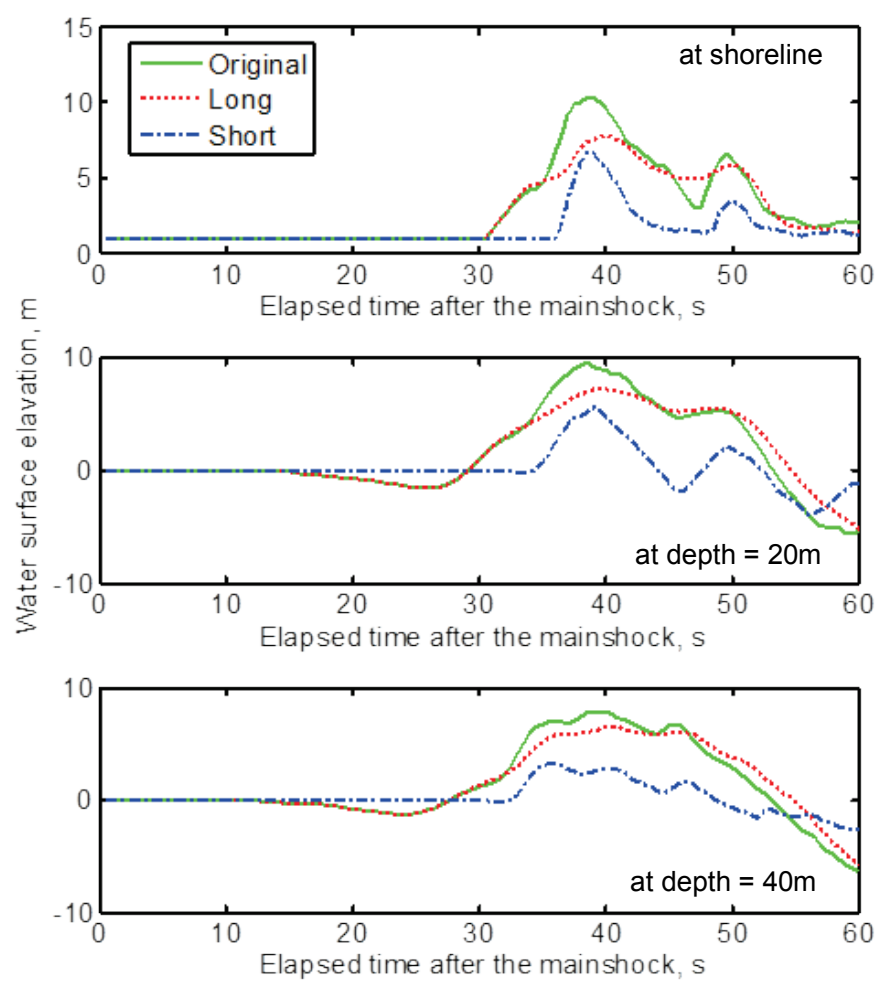

Figure 11. Water surface elevation calculated for different depths in Yamada Bay. At the depth of $40 \mathrm{~m}$, the short component wave is relatively small (Bottom panel). At the shoreline, the peak of the short component is comparable to that of the long wave component (Top panel).

In Funakoshi Bay, both components are responsible for the high runup in the region. The major geomorphological differences between the eastside of Omoe Peninsula and the region along the Funakoshi Bay are the lowland areas. The lowlands along Funakoshi Bay are a little larger than those in Omoe Peninsula. However, the most dominant factor should be the form of the bay. In the bottom panel of Figure 10, large elevation can be seen in the whole area of Funakoshi Bay. Since the incoming long component was not that different, the high elevation in Funakoshi Bay might be caused by resonance in the bay or resonance with neighboring bays.

Another finding is that the short component tends to bring very high runup at the inundation limit, but the long component gives high water elevation also at the shoreline. As for the geomorphological features, it can be concluded that the Meiji Sanriku type tsunamis will bring high runup at small inlets and lowlands facing to the epicenters, and the Jogan type tsunamis may cause severe damages along closed or partially closed bays depending on their resonant characters which vary with combinations of incoming tsunamis and bathymetries. 


\section{CONCLUSIONS}

In the present study, distributions of inundation and runup height for the 2011 off the Pacific coast of Tohoku Earthquake Tsunami were measured in and outside Yamada Bay located at the center of Iwate Prefecture, Japan. Numerical simulations were conducted to reproduce flow, inundation and runup height distributions and to investigate the relationship between the incoming tsunami waves and the responses in the areas. For the calculations, surface elevation profiles recorded by the GPS wave gauges were used as the offshore boundary condition. In order to investigate characteristics of tsunami response to different geomorphological features, frequency separation was applied to the incident tsunami wave.

This study found that;

1) Runup height of the 2011 Tohoku Tsunami inside Yamada Bay was within 6 to $8 \mathrm{~m}$, whereas runup further to the north outside of the bay was more than $20 \mathrm{~m}$.

2) Yamada Town was severely damaged, while the corresponding tsunami height was relatively low. Old sea wall parts allowed massive overtopping resulting in significant damage.

3) Numerical simulations with incident waveforms measured by GPS buoys can sufficiently reproduce the inundation by tsunami.

4) The high frequency component was responsible for large tsunami height at narrow inlets and open bays, whereas the low frequency component had significant influence for inundation in closed bays.

\section{ACKNOWLEDGMENTS}

The present study was partially supported by J-RAPID Program of Japan Science and Technology Agency (JST) and Special Project Studies for the Great East Japan Earthquake of Tokyo University of Marine Science and Technology. H.M.F. was supported by NSF award CMMI-1135768.

\section{REFERENCES}

Fritz, H. M., D. A. Phillips, A. Okayasu, T. Shimozono, H. Liu, F. Mohammed, V. Skanavis, C. E. Synolakis, and T. Takahashi. 2012. 2011 Japan tsunami current velocity measurements from survivor videos at Kesennuma Bay using LiDAR, Geophys. Res. Lett., 39, L00G23, doi:10.1029/2011GL050686.

Fujii, Y., K. Satake, S. Sakai, M. Shinohara, and T. Kanazawa. 2011. Tsunami source of the 2011 off the Pacific coast of Tohoku Earthquake, Earth Planets Space, 63, 815-820.

Geographical Survey Institute. 1961. Report on the survey of the abnormal tidal waves tsunami caused by the Chilean Earthquakes on May 24 1960, 100p.

Japan Meteorological Agency. 2012. http://www.jma.go.jp/jma/en/2011_Earthquake/2011_Earthquake.html (referred on Sep. 15, 2012).

Liu, H., T. Shimozono, T. Takagawa, A. Okayasu, H. M. Fritz, S. Sato, and Y. Tajima. 2012. The 11 March 2011 Tohoku tsunami survey in Rikuzentakata and comparison with historical events. Pure Appl. Geophys., doi:10.1007/s00024-012-0496-2 (online first, in press).

Mori, N., T. Takahashi, and the 2011 Tohoku Earthquake Tsunami Joint Survey Group. 2012. Nationwide post event survey and analysis of the 2011 Tohoku Earthquake Tsunami, Coastal Engineering Journal, JSCE, 54, 1250001 $(27 p)$.

Shimozono, T., S. Sato, A. Okayasu, Y. Tajima, H. M. Fritz, H. Liu, and T. Takagawa. 2012. Propagation and inundation characteristics of the 2011 Tohoku tsunami on the central Sanriku coast, Coastal Engineering Journal, JSCE, 54, 1250004 (17p).

The 2011 Tohoku Earthquake Tsunami Joint Survey Group. 2012. http://www.coastal.jp/tsunami2011/ index.php? Field survey results (referred on Sep. 15, 2012). 